\title{
c-Abl and Arg tyrosine kinases regulate lysosomal degradation of the oncoprotein Galectin-3
}

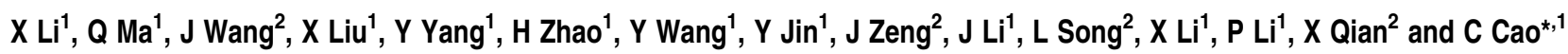

Galectin-3 (Gal3) has important roles in tumor transformation and metastasis. This study shows that c-Abl and Abl-related gene (Arg) associate with and phosphorylate Gal3. The SH (Src homology)3 domains of C-Abl/Arg bind to a P ${ }_{80}$ GPPSGP motif of Gal3, and Tyr79 and Tyr118 are the major tyrosine phosphorylation sites. A consequence of this interaction and phosphorylation is the significant impairment of chaperone-mediated autophagy of Gal3. Cells expressing Gal3 and treated with the c-Abl/Arg inhibitor STI571, Gal3-depleted cells, and Gal3-depleted cells expressing Gal3 phosphorylation mutants all display an increased sensitivity to apoptosis-inducing agents. In addition, tumor cells expressing the phosphorylation mutants show impaired tumorigenicity. These results partially explain the antiapoptotic effect of Abl and Arg. As tumors frequently overexpress Gal3, a c-Abl/Arg-specific inhibitor may potentially be applied along with other antitumor drugs to target the lysosomal degradation of Gal3 in tumor therapy.

Cell Death and Differentiation (2010) 17, 1277-1287; doi:10.1038/cdd.2010.8; published online 12 February 2010

Galectin-3 (Gal3) is a $31-\mathrm{kDa}$ galactoside-binding protein with roles in a myriad of cell processes, such as cell growth, adhesion, mitosis, proliferation, angiogenesis, pre-mRNA splicing, and, most importantly, apoptosis. ${ }^{1}$ It facilitates neoplastic progression, tumor cell survival, angiogenesis, and tumor metastasis in several human malignancies, including thyroid, gastric, breast, colon, liver, prostate, bladder, brain, and nervous system cancers. ${ }^{2}$ Cells overexpressing Gal3 are resistant to a diverse group of apoptotic stimuli by preventing mitochondrial damage, cytochrome $c$ release, and caspase activation..$^{3,4}$ The antiapoptotic activity of Gal3 is not yet completely understood. ${ }^{2}$

The mammalian Abl nonreceptor tyrosine kinase (c-Abl) and its cytoplasmic homology protein Arg (the Abl-related gene) are modular proteins with multiple functions. ${ }^{5,6}$ Both cAbl and Arg are important for cell proliferation, apoptosis, adhesion, cell migration, and stress responses. ${ }^{5,6}$ Mammalian c-Abl and Caenorhabditis elegans Abl-1 can function in either the proapoptotic or antiapoptotic pathways in response to DNA damage and other stress signals, depending on the cellular context. ${ }^{7,8}$ It is well established that nuclear $\mathrm{c}-\mathrm{Abl}$ kinase is required for DNA damage-induced apoptosis by interacting with $\mathrm{p} 53$ and $\mathrm{p} 73,{ }^{9-12}$ and that kinase active c-Abl is required in reactive oxygen species-induced apoptosis. ${ }^{13,14}$ On the other hand, progenitor B cells derived from $c$-abl knockout mice are more sensitive to apoptosis induced by growth factor deprivation and glucocorticoid treatment. ${ }^{15}$ Moreover, $\mathrm{abl}^{-/} \mathrm{arg}^{-/-}$embryos at 10.5-11 dpc exhibit widespread apoptosis in all tissues. ${ }^{16}$ Oncogenic forms of abl kinase, including Bcr-Abl, TEV-Abl, Gag-Abl, and $\Delta \mathrm{SH} 3$ $\mathrm{Abl}$, are strong inhibitors of apoptosis. ${ }^{17-20}$ Furthermore, C. elegans Abl-1 can antagonize p53-mediated germline apoptosis after ionizing irradiation. ${ }^{21}$ Thus, c-Abl/Arg has both positive and negative roles in apoptosis depending on the cellular context. ${ }^{22}$ Several observations suggest that the cytoplasmic localization of $\mathrm{c}$-Abl is required for antiapoptotic function. ${ }^{23,24}$ However, the signals that mediate its antiapoptotic effect are largely unknown.

In this paper, we report that Gal3 interacts with and is phosphorylated by the nonreceptor tyrosine kinases c-Abl and Arg, and that the lysosomal-dependent proteolysis of Gal3 is efficiently blocked by the kinases.

\section{Results}

c-Abl and Arg associate with Gal3. Using a yeast twohybrid analysis, we previously showed that c-Abl associates with Gal3. To substantiate the interaction between c-Abl and Gal3, anti-Gal3 immunoprecipitates of human MCF-7 cells were analyzed by immunoblotting with anti-c-Abl. Immunoblotting showed that $\mathrm{c}-\mathrm{Abl}$ was present in the anti-Gal3 immunoprecipitate, but not in the immunoprecipitate using mouse IgG (belonging to the same subclass) (Figure 1a). To confirm the interaction specificity, Gal3 was knocked down by RNAi, and c-Abl was undetectable in anti-Gal3 immunoprecipitates from MCF-7/gal3 RNAi cell lysates (Figure 1a). In a reciprocal experiment, Gal3 was found in anti-c-Abl, but not in rabbit IgG, immunoprecipitates (Figure 1b). The c-Abl:Gal3 complex was not disrupted in the presence of lactose, which indicated that the Abl:Gal3 interaction was not mediated through glycoproteins with which c-Abl might interact (Figure 1b). To further show that the interaction occurred in the cell, MCF-7 cells were treated

\footnotetext{
${ }^{1}$ Beijing Institute of Biotechnology, Beijing, China and ${ }^{2}$ Beijing Proteome Research Center, Beijing, China

${ }^{*}$ Corresponding author: C Cao, Department of Molecular Biology, Beijing Institute of Biotechnology, PO Box 130(8), 27 Taiping Road, Beijing 100850, China. Tel: + 86106815 5151; Fax: + 86106385 3882; E-mail: caoc@ @ic.bmi.ac.cn

Keywords: c-Abl; Arg; Galectin-3; autophagy; apoptosis

Abbreviations: Arg, Abl-related gene; SH, Src homology; GST, Glutathione S-transferase; STS, staurosporine; 3MA, 3-methyladenine; ConA, Concanamycin A; PepA, pepstatin A; Gal3, Galectin-3; PFA, paraformaldehyde; CMA, chaperone-mediated autophagy

Received 16.10.09; revised 15.12.09; accepted 29.12.09; Edited by G Rabinovich; published online 12.2.10
} 


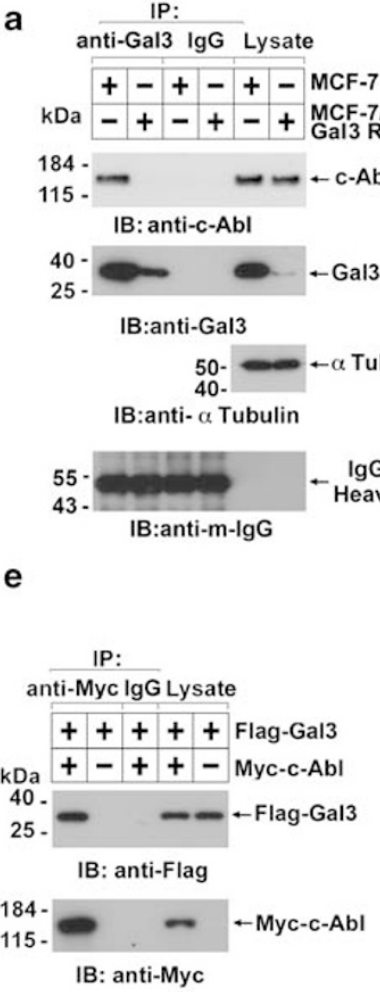

b

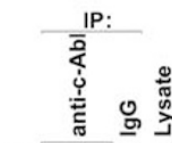

$\begin{array}{llllll}\mathrm{kDa} & 0 & 25 & 0 & 0 & \mathrm{mM} \text { Lactose }\end{array}$

25- - - - - Gal3

IB:anti-Gal3

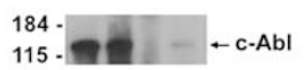

IB: anti-c-AbI

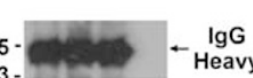

IB:anti-r-IgG c

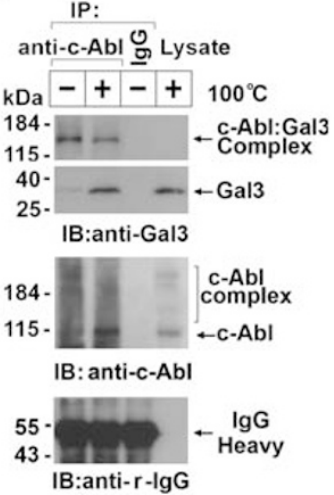

d

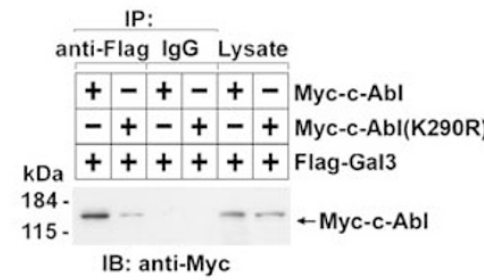

25. - - -Flag-Gal3

IB: anti-Flag f

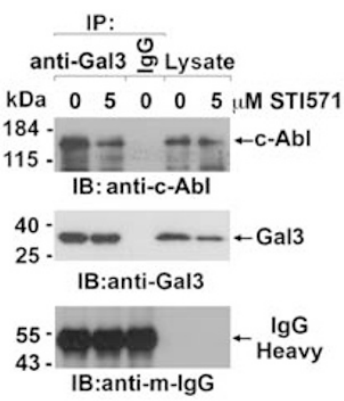

g

\section{MCF-7/Scr MCF-7/Gal3 RNAi}

anti-Gal3 on anti-Gal3 O MCF-7/Scr MCF-7/Gal3 RNAi

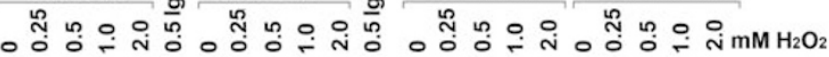

웄운 뚱

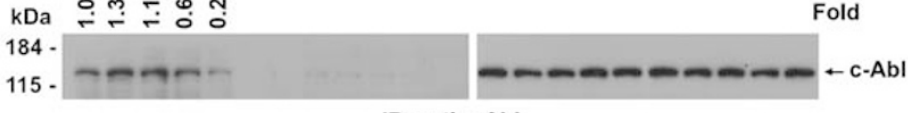

|B: anti-c-Ab|

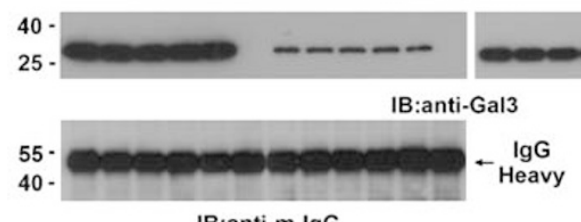

IB:anti-m-IgG

j
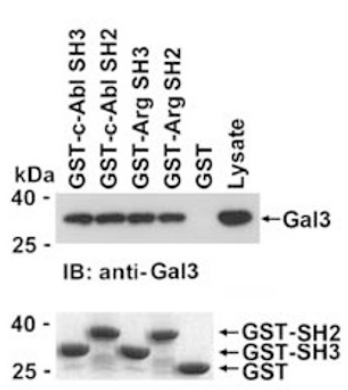

Coomassie Blue Staining i

Flag-Galectin 3

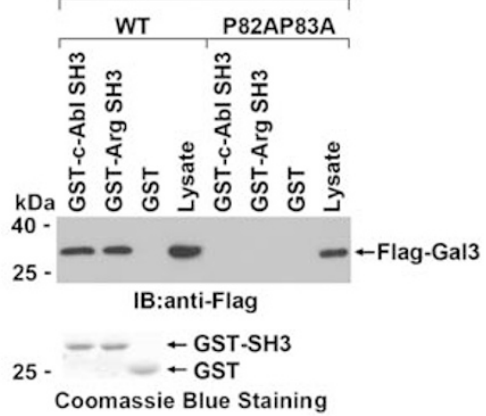

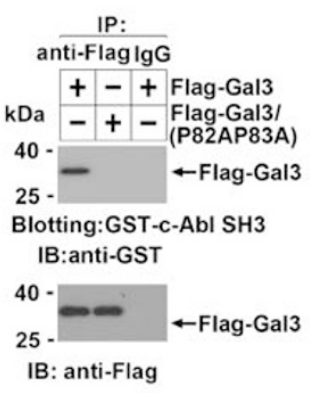

k

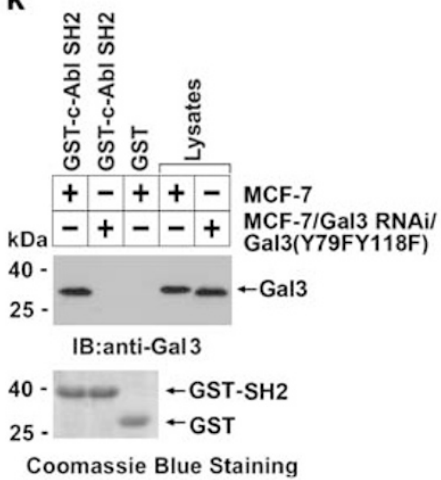

Figure 1 c-Abl and Arg associate with Gal3. (a) Lysates from MCF-7 or MCF-7/gal3 RNAi cells were subjected to immunoprecipitation with anti-Gal3 or normal mouse IgG1 as control, and were subsequently analyzed by immunoblotting with anti-Gal3, anti-c-Abl, or anti-mouse lgG. (b) Lysates from MCF-7 cells were subjected to immunoprecipitation with anti-c-Abl in the presence of 0 or $25 \mathrm{mM}$ lactose and analyzed by immunoblotting with anti-Gal3 or anti-c-Abl. (c) MCF-7 cells were treated with or without PFA for $30 \mathrm{~min}$ and the lysates subjected to immunoprecipitation with anti-c-Abl. The lysates were analyzed by immunoblotting with anti-Gal3 or anti-c-Abl. (d, e) 293T cells were cotransfected with Flag-Gal3 and Myc-c-Abl or Myc-c-Abl(K290R)-expressing plasmids. The anti-Flag (d) or anti-Myc (e) immunoprecipitates were analyzed by immunoblotting with anti-Myc or anti-Flag. (f) Lysates from MCF-7 cells treated with or without $5 \mu \mathrm{M} \mathrm{STI571} \mathrm{for} 8 \mathrm{~h}$ were subjected to immunoprecipitation with anti-Gal3. After normalization for the Gal3 level, the adsorbates were subsequently analyzed by immunoblotting with anti-c-Abl or anti-Gal3. (g) MCF-7/Scramble or MCF-7/ga/3 RNAi cells were treated with the indicated concentration of $\mathrm{H}_{2} \mathrm{O}_{2}$. The anti-Gal3 immunoprecipitates were analyzed by immunoblotting with anti-c-Abl and anti-Gal3. (h) Lysates from MCF-7 cells or (i) 293 cells expressing Flag-Gal3 or Flag-Gal3(P82AP83A) were incubated with the indicated GST fusion protein or GST for $2 \mathrm{~h}$. The adsorbates were analyzed by immunoblotting with anti-Flag. (j) Anti-Flag or lgG immunoprecipitates from cells transfected with Flag-Gal3 or Flag-Gal3(P82AP83A) were blotted onto nitrocellulose membrane. The nitrocellulose membrane was incubated with soluble GST-c-Abl SH3 for $2 \mathrm{~h}$ and then analyzed with anti-GST or anti-Flag antibody. (k) Lysates from MCF-7 and MCF-7/gal3 RNAi/gal3(Y79FY118F)-stable cells were incubated with GST-c-Abl-SH2 or GST agarose beads for $2 \mathrm{~h}$. The adsorbates were analyzed by immunoblotting with anti-Gal3

with the reversible chemical cross-linker PAF. Immunoblotting of anti-c-Abl immunoprecipitates with anti-Gal3 showed the presence of the Gal3:c-Abl complex, which was disrupted by incubating at $100^{\circ} \mathrm{C}$ for $30 \mathrm{~min}$ (Figure 1c). In addition, 293T cells were cotransfected with Flag-Gal3 and Myc-c-Abl. Anti-Flag immunoprecipitation showed an 
a

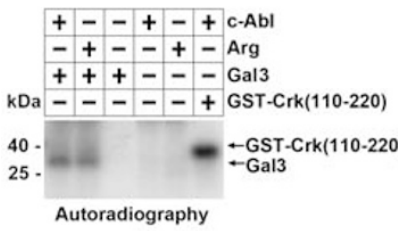

d

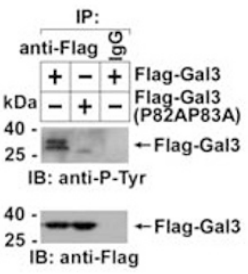

e b

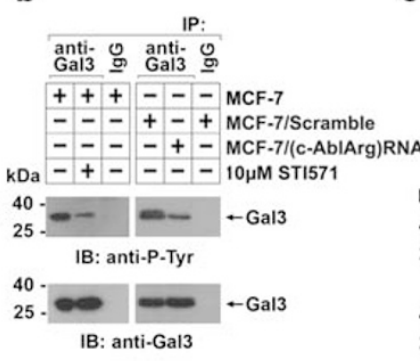

C

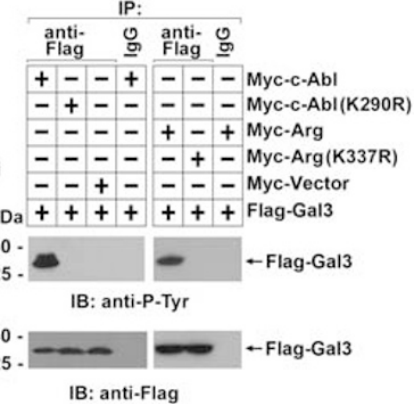

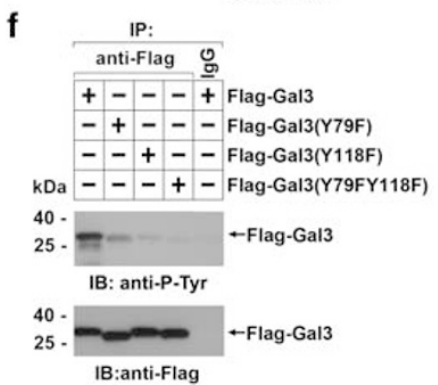

Figure 2 Gal3 was phosphorylated by c-Abl and Arg. (a) Recombinant Gal3 $(0.5 \mu \mathrm{g})$ or GST-Crk(110-220) was incubated with $10 \mathrm{ng}$ of human Abl or Arg protein (Upstate Biotechnology Inc.) in the presence of $\left[\gamma^{32} \mathrm{P}\right]$ ATP. The reaction products were analyzed by autoradiography. (b) MCF-7 cells were treated with or without $10 \mu \mathrm{M}$ STI571 for $12 \mathrm{~h}$. Anti-Gal3 immunoprecipitates were normalized by the Gal3 level, and then analyzed by immunoblotting with anti-P-Tyr or anti-Gal3 (left). Lysates of PepA-treated MCF7/Scramble or MCF-7/(c-abl + arg) RNAi cells were immunoprecipitated with anti-Gal3, and the immunoprecipitates were analyzed by immunoblotting with anti-P-Tyr or antiGal3 after normalization (right). (c) $c$-abl ${ }^{-1}$ arg $^{-/}$MEF cells were cotransfected with the indicated vectors. Anti-Flag immunoprecipitates were analyzed by immunoblotting with anti-P-Tyr or anti-Flag. (d) $\mathrm{c}$-abl ${ }^{-1}$ arg $^{-1-}$ MEF cells were cotransfected with Myc-c-Abl and Flag-Gal3 or Flag-Gal3(P82AP83A). Anti-Flag and lgG immunoprecipitates were analyzed by anti-P-Tyr or anti-Flag. (e) MCF-7 cells were treated with $\gamma$-irradiation at the indicated dosage. Anti-Gal3 immunoprecipitates were analyzed by immunoblotting with anti-P-Tyr or anti-Gal3. (f) 293T cells were cotransfected with myc-c-Abl and Flag-Gal3 or Flag-Gal3 mutants. Anti-Flag immunoprecipitates were analyzed by immunoblotting with anti-P-Tyr or anti-Flag

associated Myc-c-Abl protein in anti-Myc immunoblotting (Figure 1d). A kinase inactive form of c-Abl (c-Abl(K290R), in which the lysine residue in position 290 was replaced by arginine) was observed to interact with Gal3, but to a significantly lesser extent (Figure 1d). Reciprocally, an immunoblot analysis of anti-Myc immunoprecipitates with anti-Flag showed an association between Myc-C-Abl and Flag-Gal3 (Figure 1e). Moreover, Myc-Gal3 was found in anti-Flag immunoprecipitates prepared from cells expressing Myc-Gal3 and Flag-c-Abl (Supplementary Figure 1a). In concert with these findings, an endogenous c-Abl:Gal3 interaction was partially disrupted by the Abl/Arg inhibitor, STI571 (Figure 1f). The Arg kinase also formed complexes with Gal3 (Supplementary Figure 1b). It is known that c-Abl is activated by a low level of $\mathrm{H}_{2} \mathrm{O}_{2}{ }^{13}$ or irradiation, ${ }^{25}$ whereas a high concentration of $\mathrm{H}_{2} \mathrm{O}_{2}$ results in the inactivation of c-Abl. ${ }^{14}$ We found that treatment with 0.25 and $0.5 \mathrm{mM}$ $\mathrm{H}_{2} \mathrm{O}_{2}$ results in the slightly increased formation of c-Abl: Gal3 complexes, whereas higher $\mathrm{H}_{2} \mathrm{O}_{2}(>1 \mathrm{mM})$ yielded decreased associations (Figure 1g). As a control, little, if any, c-Abl was present in anti-Gal3 immunoprecipitates of MCF-7/ gal3 RNAi cells (Figure 1g). Similar findings were obtained when the cells were treated with $\gamma$-irradiation (Supplementary Figure 1c). These findings indicate that endogenous $\mathrm{c}-\mathrm{Abl}$ and Arg constitutively associate with endogenous Gal3, but an increased association is observed with enhanced kinase activity.

To further define the interaction between c-Abl and Gal3, lysates from MCF-7 cells were incubated with glutathione
S-transferase (GST) or GST fusion proteins. An immunoblot analysis with anti-Gal3 antibody showed the binding of Gal3 to both the Src homology (SH)3 and $\mathrm{SH} 2$ domains of c-Abl and Arg (Figure 1h). Gal3 contains a potential SH3-binding motif (Y ${ }_{79}$ PGPPSGP). In contrast to Gal3, the binding of c-Abl SH3 or Arg SH3 was eliminated with Gal3(P82AP83A), in which the proline residues in position numbers 82 and 83 of Gal3 were replaced by a similar amino-acid residue alanine (Figure 1i). To rule out indirect binding mediated by other components in the cell lysate, Flag-Gal3 or Flag-Gal3(P82AP83A) was subjected to SDS-PAGE. Blotting with soluble GST-c-Abl SH3, followed by anti-GST antibody, showed that c-Abl SH3 binds directly to Gal3 but not to Gal3(P82AP83A) (Figure 1j). An association between c-Abl and Gal3 but not Gal3(P82AP83A) indicates that the motif is important for the interaction (Supplementary Figure 1d). Moreover, the c-Abl $\mathrm{SH} 2$ domain could not bind to Gal3(Y79FY118F), a mutant in which tyrosine residues at amino-acid residues 79 and 118 were replaced by a similar unphosphorylatable amino-acid residue phenylalanine (Supplementary Figure 1e). This mutant could not be phosphorylated by c-Abl or Arg. (Figures $1 \mathrm{k}$ and 2f). These findings show that $\mathrm{c}-\mathrm{Abl}$ and Arg bind directly to Gal3 through interactions governed by $\mathrm{SH} 3$ domains and the PGPPSGP proline-rich motif of Gal3, as well as $\mathrm{SH} 2$ domains and the potentially phosphorylated tyrosine residues of $\mathrm{Gal3}$.

Gal3 was phosphorylated by c-Abl and Arg. The association between Gal3 and c-Abl/Arg suggests that 


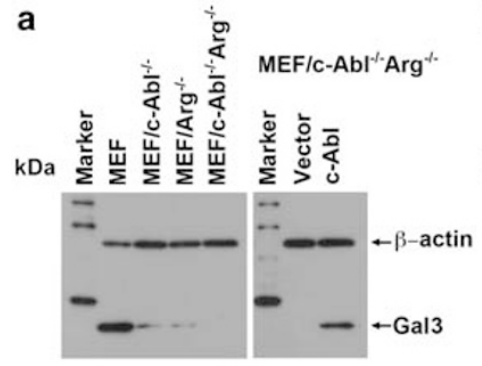

IB:anti-Gal 3 + anti- $\beta$-Actin b

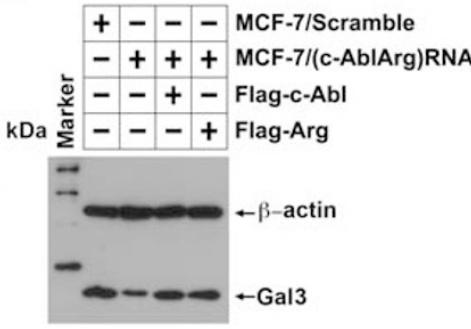

IB:anti-Gal3 + anti- $\beta$-Actin
C

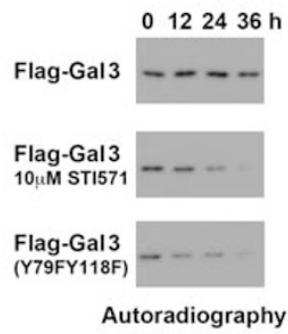

d

e

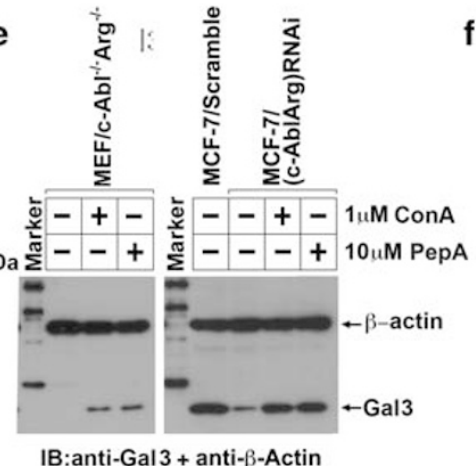

f

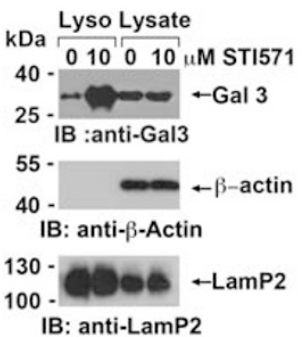

Figure 3 The c-Abl/Arg phosphorylation inhibits Gal3 autophagy. $(\mathbf{a}, \mathbf{b})$ Lysates from the indicated cells were analyzed by immunoblotting with anti-Gal3 and anti- $\beta$-actin

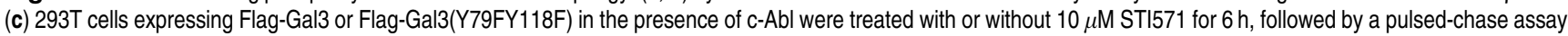
(d) MCF-7 cells were treated with STI571 and/or ConA at the indicated concentration for $16 \mathrm{~h}$. Cell lysates were subjected to immunoblotting with the indicated antibodies. (e) $c-a b F^{/-}$arg $^{-/-}$MEF cells (left two panels) or MCF-7/(c-abl + arg) RNAi cells (right panel) were treated with or without $1 \mu \mathrm{M}$ ConA or $10 \mu \mathrm{M}$ PepA for $16 \mathrm{~h}$. Cell lysates were

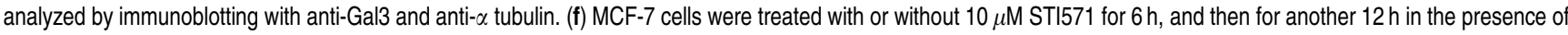
$10 \mu \mathrm{M}$ PepA. Lysosomes were prepared and analyzed by immunoblotting with the indicated antibodies

Gal3 is a substrate for these tyrosine kinases. To confirm that Gal3 is phosphorylated in vitro, $0.5 \mu \mathrm{g}$ recombinant Gal3 was incubated with c-Abl or Arg in the presence of $\left[\gamma_{-}{ }^{32} \mathrm{P}\right]-\mathrm{ATP}$. An analysis of the reaction products showed the phosphorylation of Gal3 (Figure 2a). Immunoblotting of anti-Gal3 immunoprecipitates from MCF-7 cell lysates with an anti-phosphotyrosine (P-Tyr) antibody showed that Gal3 was constitutively phosphorylated and that the phosphorylation was significantly inhibited by STI571 (Figure 2b, left). Substantially less Gal3 tyrosine phosphorylation was found in MCF-7/(c-abl+arg) RNAi cells compared with MCF-7/Scramble cells (Figure 2b, right; Supplementary Figure 2a). Moreover, Gal3 was phosphorylated by C-Abl and Arg but not by kinase inactive $\mathrm{c}-\mathrm{Abl}(\mathrm{K} 290 \mathrm{R})$ or $\mathrm{Arg}(\mathrm{K} 337 \mathrm{R})$, in which the lysine at the amino-acid residue 290 or 337, respectively, was replaced by similar arginine (Figure 2c). In agreement with the findings that Gal3 binds to $\mathrm{c}-\mathrm{Abl}$ through the Y79PGPPSGP motif, Gal3(P82AP83A) was not phosphorylated by c-Abl (Figure 2d). Consistent with the findings that the association between c-Abl and Gal3 was regulated by oxidative stress and irradiation, increased phosphorylation was observed when MCF-7 cells were treated with $<10 \mathrm{~Gy} \gamma$-irradiation (Figure $2 \mathrm{e}$ ) or $0.25-0.5 \mathrm{mM} \mathrm{H}_{2} \mathrm{O}_{2}$ (Supplementary Figure $2 \mathrm{c}$ ), and decreased significantly at higher dosages (Figure $2 \mathrm{e}$ and Supplementary Figure 2c).

We next evaluated the c-Abl and Arg phosphorylation sites on Gal3. Flag-Gal3 was cleaved by thrombin at R129 and then subjected to immunoblotting by anti-P-Tyr. Only the $\mathrm{N}$ terminal of Flag-Gal3(1-129), but not Gal3(130-253), was shown to be tyrosine phosphorylated (Supplementary Figure 2d; data not shown). As the $\mathrm{N}$ terminal of Gal3 could not be cleaved by any specific proteases for mass spectrometry (MS)/MS analysis, we digested Flag-Gal3 (expressed in the presence of c-Abl) with a less specific elastase and then analyzed the peptides by liquid chromatography (LC)/MS/MS. The results suggested that $Y 79$ was phosphorylated (data not shown). When we further mutated Y79 to a similar aminoacid residue phenylalanine $(F)$, tyrosine phosphorylation decreased, but was not eliminated (Figure 2f), which suggests that there was more than one tyrosine phosphorylation site on Gal3. The tyrosine residues on Gal3 (1-129) were then individually mutated, and the results suggested that the $\mathrm{Y} 118 \mathrm{~F}$ mutation also resulted in a substantial decrease in tyrosine phosphorylation (Figure $2 f$ and Supplementary Figure 2d). Therefore, the tyrosine phosphorylation of Gal3 primarily occurs on Y79 and is potentially but not actually confirmed by MS/MS on Y118.

c-Abl/Arg-dependent phosphorylation inhibits lysosomal-dependent degradation of Gal3. To confirm that $\mathrm{c}-\mathrm{Abl}$ and Arg regulate Gal3 levels in cells, cell lysates from wild-type, $c-a b l^{-1-}$, $\mathrm{arg}^{-1-}$, or $c$ - $a b^{I^{\prime-}} \mathrm{arg}^{-1-}$ mouse embryo fibroblast (MEF) cells were analyzed by immunoblotting with anti-Gal3. Gal3 protein levels were decreased in $\mathrm{c}^{-a b l^{-1-}}$ and $\mathrm{arg}^{-1-}$ MEF cells and, to a 
greater extent, in $c-a b l^{\prime-} a^{-1-}$ MEF cells (Figure 3a, left). The exogenous Myc-c-Abl expression in $c-a b l^{l-} \mathrm{arg}^{-1-} \mathrm{MEF}$ cells partially restores Gal3 protein levels (Figure 3a, right). Gal3 protein levels were also found to be significantly decreased in MCF-7/(c-abl+arg) RNAi cells, and the expression could be rescued by the overexpression of $\mathrm{c}$ Abl or Arg in which three nucleotides at the 3rd position of amino-acid codon in the RNAi-targeting sequence was mutated (Figure 3b). An analysis of Gal3 in the medium showed that $\mathrm{c}-\mathrm{Abl} / \mathrm{Arg}$ regulates intracellular Gal3 levels by a mechanism other than protein secretion because no more Gal3 was secreted into the medium by MCF-7/(c-abl+arg) RNAi cells (Supplementary Figure 3a). Similarly, when 293 cells were transfected with the same amount of Flag-tagged Gal3 and mutants, the expression levels of FlagGal3(Y79FY118F) and Flag-Gal3(P82AP83A), which cannot be phosphorylated by c-Abl/Arg, decreased significantly. Treatment with the c-Abl/Arg inhibitor also resulted in decreased expression of Gal3 (Supplementary Figure $3 b)$. To investigate whether c-Abl and Arg regulate the Gal3 protein half-life, pulse-chase assays were performed using Flag-Gal3 and Flag-Gal3(Y79FY118F)-expressing 293T cells in the presence of 0 or $10 \mu \mathrm{M}$ STI571, respectively. Flag-Gal3 had a half-life of $>40 \mathrm{~h}$, whereas the half-life was significantly reduced to $\sim 25 \mathrm{~h}$ in cells treated with STI571 (Figure 3c). In addition, the half-life of Flag-Gal3(Y79FY118F) was also reduced to $\sim 18 \mathrm{~h}$ in the absence of STI571 (Figure 3c). As controls, little if any effect was observed on other abundant proteins in these assays (Supplementary Figure 3c). It is noted that the downregulation of Gal3 levels could be restored by treating cells with the lysosome inhibitor Concanamycin A (ConA) (Figure 3d) or lysosomal protease inhibitor pepstatin $A$ (PepA) (Supplementary Figure 3d), but not with the proteasome inhibitor lactacystin (data not shown). Gal3 expression was also observed to be partially restored when $c-a b l^{-1-} \mathrm{arg}^{-1-}$ MEF cells and MCF-7/(c-abl+arg) RNAi cells were treated with ConA or PepA (Figure $3 e$ ). In agreement with the findings that a high concentration of $\mathrm{H}_{2} \mathrm{O}_{2}$ inhibits Gal3 phosphorylation, Gal3 level decreased significantly on treatment with $1 \mathrm{mM} \mathrm{H}_{2} \mathrm{O}_{2}$ for $\geqslant 8 \mathrm{~h}$ (data not shown). Furthermore, immediately after STI571 treatment, Gal3 was preferentially bound to lysosomes when compared with other lysosomal degradable proteins, such as $\mathrm{lkB} \alpha^{26}$ (Figure $3 f$ and Supplementary Figure 3f).

To further show that c-Abl/Arg regulates Gal3 levels by preventing its lysosomal degradation, MCF-7 cells were treated with STI571 or its solvent (DMSO), and stained with anti-Gal3 and anti-Lamp2, a molecular marker of lysosomes. Gal3 was found to be distributed in both the cytoplasm and the nuclear compartments (Figure 4a, upper panel). In contrast, STI571-treated wild-type MCF-7 cells, but not cells expressing STI571-resistant c-Abl, resulted in a decreased level of cellular Gal3, which was found to be accumulated in lysosomes (Figure 4a, second and third rows; Figure 4b, upper panel). Far more Gal3 was accumulated in lysosomes when cells were treated with STI571 in the presence of the lysosomal inhibitor PepA (Figure 4a, fourth and fifth rows; Figure 4b, lower panel). Moreover, the expression of Gal3 was rescued, and the protein was found to be accumulated in lysosomes by treating MCF-7/(c-abl+arg) RNAi cells with lysosomal inhibitors, whereas Gal3 expression was undetectable by immunostaining in the absence of lysosomal inhibitors (Figure 4a sixth row; Figure 4b, lower panel). However, the unphosphorylated Gal3 mutants expressed in MCF-7/gal3 RNAi cells were also found to aggregate in the lysosomes (Figure 4c, upper two panels; Figure 4d; data not shown). Moreover, wild-type Gal3 was also observed to accumulate in lysosomes when they were stably expressed in MCF-7/ $(c-a b l+a r g)$ RNAi cells (Figure 4c, lower two panels; Figure 4d). Similar results were obtained with other Gal3expressing tumor cell lines (such as HeLa, H1229, A549, HCT116; data not shown). These data collectively show that, in the absence of kinase active c-Abl and Arg, Gal3 is accumulated in lysosomes and degraded through the lysosomal pathway.

\section{c-Abl and Arg block Gal3 degradation by chaperone-} mediated autophagy. Chaperone-mediated autophagy (CMA) is known to occur by transport of the target protein to the lysosomal lumen, mediated by HSC70 and Lamp2. ${ }^{27}$ When MCF-7 cells were treated with STI571, Gal3 aggregated with the localization of HSC70 in the lysosome (Figure 5a, left and right panels). However, no Gal3 complexes were observed with LC3, a molecular marker of autophagic vacuoles (AVs) (Figure 5a, lower panel). The lysosomal degradation of Gal3 in the presence of STI571 could be blocked by the lysosomal selective inhibitor ConA, but not by the AV-selective inhibitor 3-methyladenine (3MA) (Figures 3d and e, 5b). Moreover, significantly more HSC70:Gal3 complexes were found by coimmunoprecipitation from the cells treated with STI571 (Figure 5c). In agreement with these findings, Flag-Gal3(P82AP83A) and Flag-Gal3(Y79FY118F) were found to bind to HSC70 to a greater extent than wild-type Gal3 (Figure $5 \mathrm{~d}$ ). These results suggest that Gal3 is degraded through CMA, but not microautophagy or macroautophagy, when it cannot be phosphorylated by c-Abl or Arg.

The c-Abl/Arg-mediated phosphorylation of Gal3 regulates cell apoptosis and tumorigenesis. The effect of tyrosine phosphorylation of Gal3 by c-Abl and Arg on cell apoptosis was assessed. As expected, the depletion of Gal3 by RNAi resulted in significantly more cell apoptosis, as shown by the treatment of cells with $10 \mathrm{~Gy}$ IR or $0.5 \mathrm{mM}$ $\mathrm{H}_{2} \mathrm{O}_{2}$, and the antiapoptotic effect of Gal3 was rescued by the expression of wild-type Gal3 but not Gal3(Y79FY118F) (Figure 6a; data not shown). Similar results were obtained when the cells were treated with other apoptotic stimuli reagents, such as cisplatin or staurosporine (STS). Interestingly, even more apoptotic cells were observed in the context of Gal3(P82AP83A) expression compared with the gal3 knockdown cell line (Figure $6 \mathrm{~b}$ and data not shown). It was also found that Gal3 degradation induced by the c-Abl/Arg inhibitor STI571 was synergized by apoptotic stimuli, such as STS (Figure 5b). To address this mechanism, we analyzed caspase activation and found that caspase 2 and caspase 6 , but not caspase 9 or caspase 12, were activated more by STS treatment in MCF-7/gal3 RNAi cells (Figure 6c). Caspase activation was attenuated by the expression of 
a
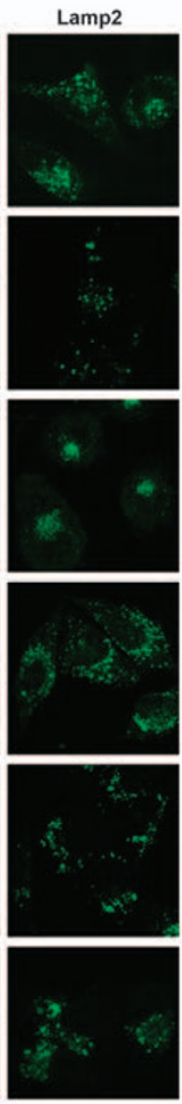

C MCF-7/Gal3 RNA
/Gal3
PepA

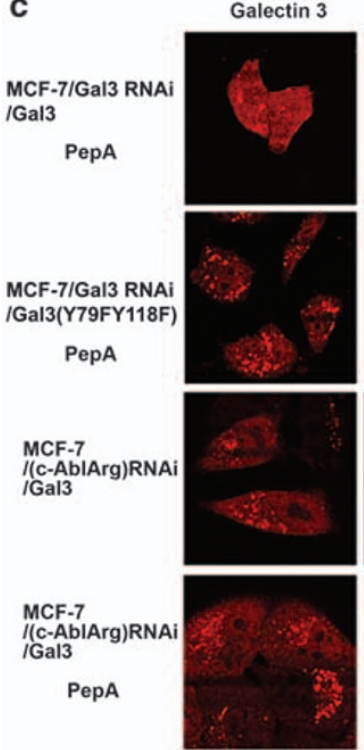

Galectin 3
Lamp2

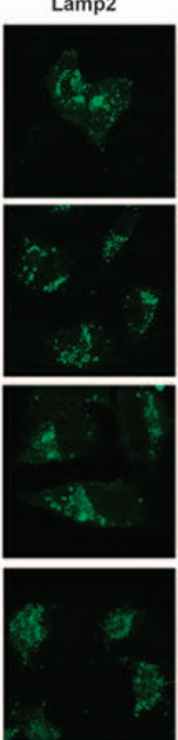

Nuclear
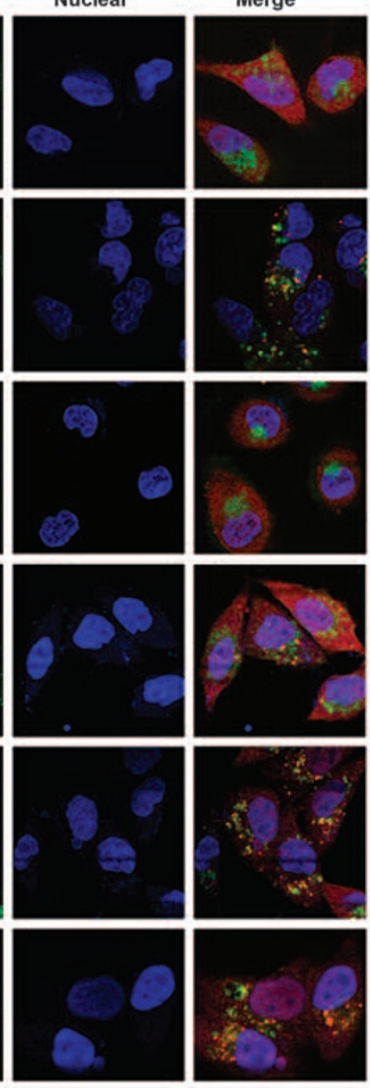

Nuclear
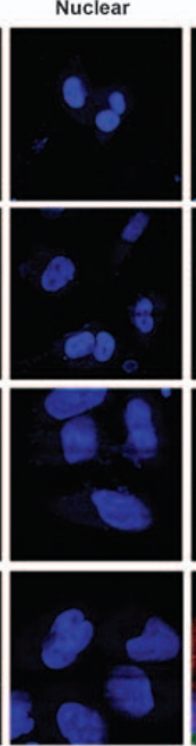

Merge
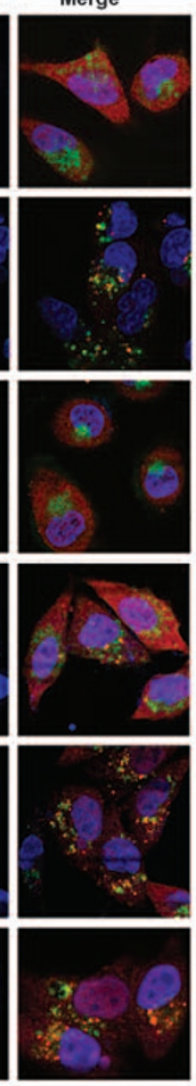

Merge
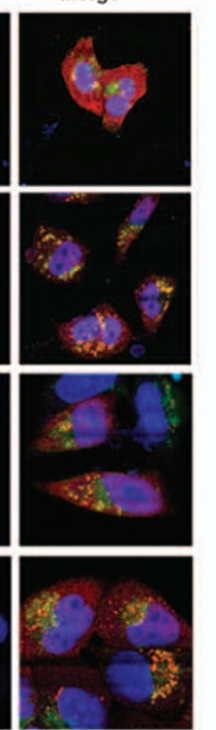

b
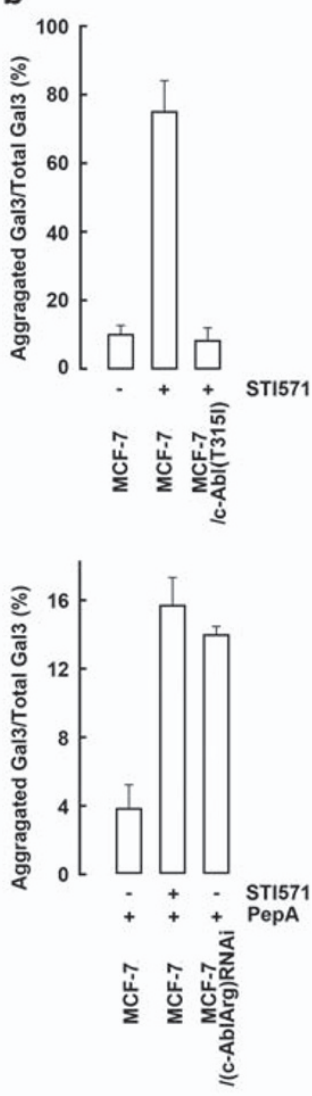

d
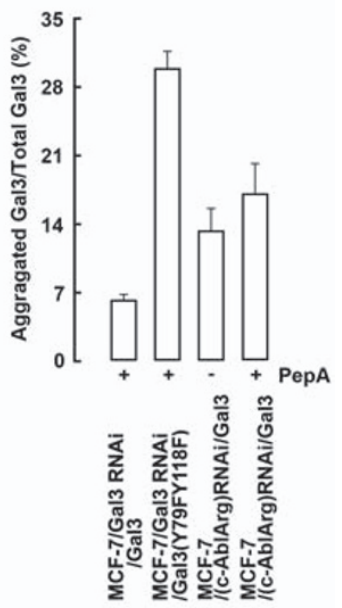

Figure 4 The c-Abl/ Arg phosphorylation inhibits lysosomal accumulation of Gal3. (a, c) The indicated cell lines were treated with or without STI571 and/or PepA, stained with anti-Gal3, anti-Lamp2 and Hoechst 33342, and then subjected to analysis by laser confocal microscopy. (b, d) Percentage of Galectin-3 accumulated in lysosomes was assessed

wild-type Ga/3 but not ga/3(Y79FY118F). Increased mitochondrial cytochrome $c$ release, mitochondrial potential loss, and PARP cleavage was also observed in MCF-7/gal3 RNAi and MCF-7/gal3 RNAi/Gal3Y79FY118F) cells compared with wild-type MCF-7 and MCF-7/ga/3 RNAi/ga/3 cells (Figure 6d). These findings are supported by an earlier report that STS induces the apoptosis of MCF-7, a caspase 3-deficient cell line, by the activation of caspase $6 .^{28}$ Moreover, Gal3 and Gal3(Y79FY118F) were expressed in c-Abl/Arg-depleted cells (Supplementary Figure 4a). In 

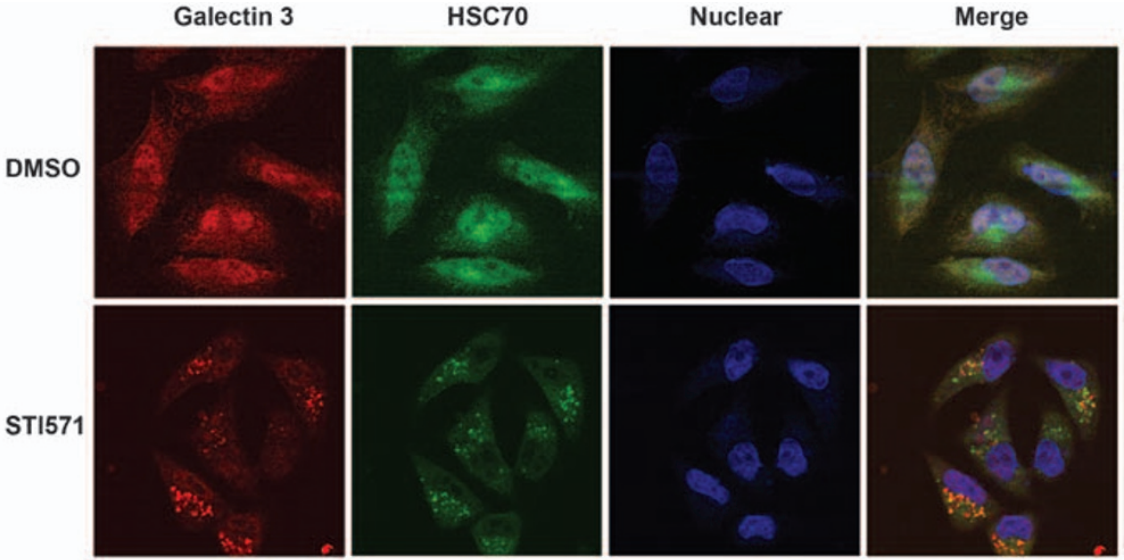

b

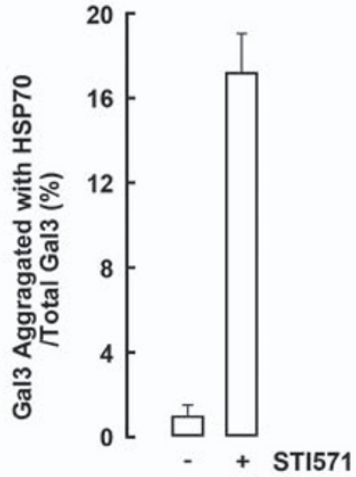

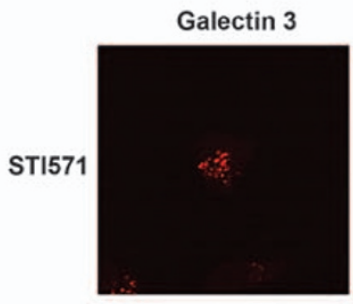
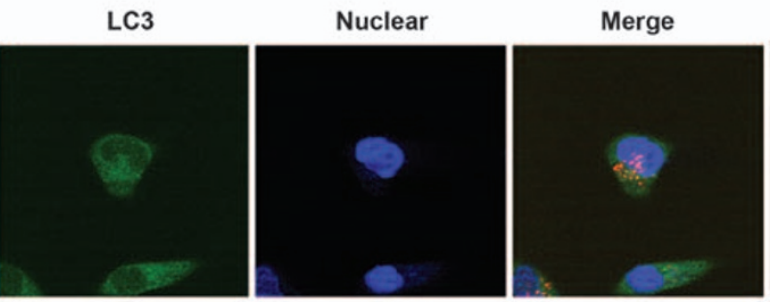

C

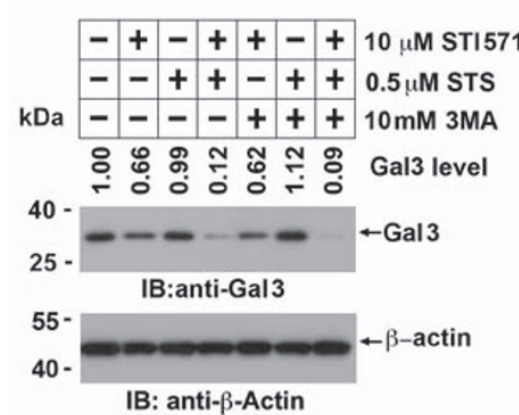

d

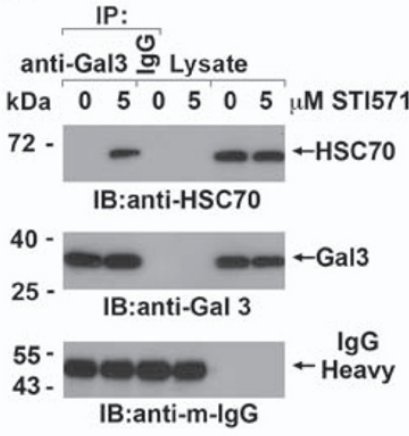

e

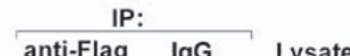

IB:anti-HSC70

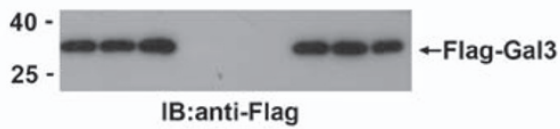

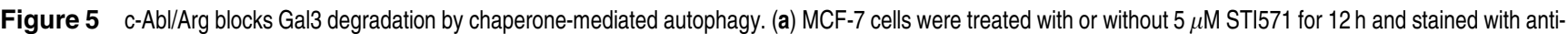
Gal3 and anti-HSC70 (upper left panel) or anti-LC3 (lower left panel). The percentage of Galectin-3 accumulated with Hsp70 was accessed (right panel). (b) MCF-7 cells were treated with STI571, STS and/or 3MA for $8 \mathrm{~h}$ and the cell lysates analyzed by immunoblotting with anti-Gal3 and anti- $\beta$-actin. (c) Anti-Gal3 immunoprecipitates from MCF-7 cells treated with 0 or $5 \mu \mathrm{M} \mathrm{STI571}$ were analyzed by immunoblotting with anti-Gal3 and anti-HSC70. (d) 293T cells were transfected with $1 \mu \mathrm{g} \mathrm{Flag-Gal3,} 4 \mu \mathrm{g} \mathrm{Flag-}$ Gal3(P82AP82A), or $4 \mu \mathrm{g}$ Flag-Gal3(Y79FY118F). (e) Anti-Flag immunoprecipitates were analyzed with anti-HSC70 and anti-Flag

agreement with the findings that $\mathrm{C}-\mathrm{Abl}^{-/} \mathrm{Arg}^{-1-} \mathrm{MEF}$ cells are more sensitive to apoptotic stimuli, ${ }^{14,16}$ MCF-7/ $(c-a b l+a r g)$ RNAi cells were sensitized to apoptotic stimuli by STS (Figure 6e). This was slightly attenuated by the overexpression of wild-type Gal3 and to a lesser extent by Gal3(Y79FY118F) (Figure 6e). To further address the c-Abl/Arg-dependent antiapoptotic property of Gal3, a similar investigation was carried out in HeLa cells, and consistent results were obtained (Figure $6 f$ and Supplementary Figure 4b). Caspase 3 and caspase 6 were found to be activated more by STS treatment in HeLa/Gal3 RNAi cells (data not shown). Gal3 expression exhibited little, if any, effect on cell apoptosis in c-Abl/Arg-depleted cells (Figure 6f). These data collectively show that the antiapoptotic activity of Gal3 is dependent on the presence of c-Abl and Arg.
Gal3 is considered to be an oncogenic protein. ${ }^{29}$ To investigate whether $\mathrm{C}-\mathrm{Abl}$ and $\mathrm{Arg}$ regulate the tumorigenic effects of Gal3, MCF-7/gal3 RNAi cells and the same cells rescued by the expression of wild-type or non-phosphorylated Gal3 were injected into the flanks of nude mice. Tumor growth was significantly repressed for tumors originating in MCF-7/gal3 RNAi cells. Furthermore, the phenotype was rescued by the expression of wild-type Gal3 but not the non-phosphorylated Gal3 mutants. In agreement with the findings from the in vitro apoptosis assay in Figure $6 a$, tumors induced by MCF-7/gal3 RNAi cells rescued by the expression of unphosphorylated Gal3(P82AP83A) or GaI3(Y79FY118F) were significantly smaller than the MCF-7/ gal3 RNAi cells. No tumors were observed in the three and four mice, respectively, of the seven inoculated mice per group (Figures 7a, c). Consistent with the findings that MCF-7/ 

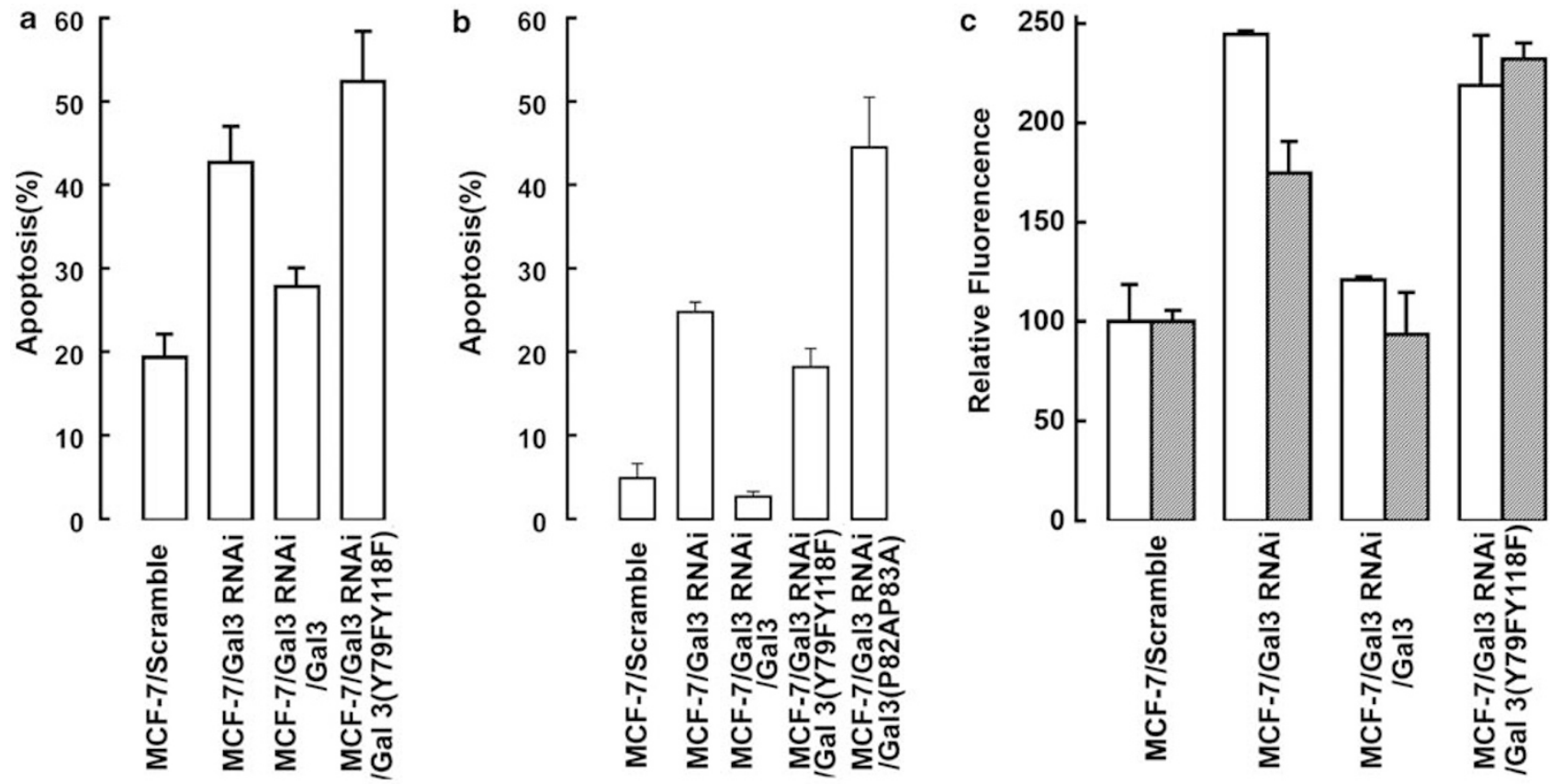

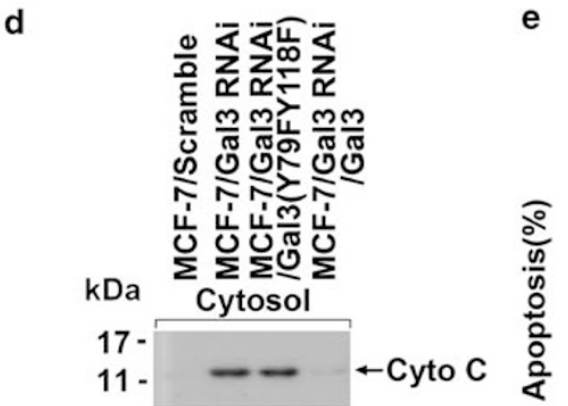

IB:anti-Cytochrome C

IB:anti-HSP60
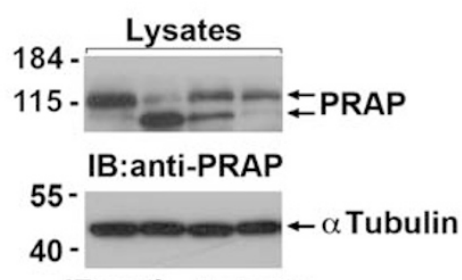

IB:anti- $\alpha$ Tubulin

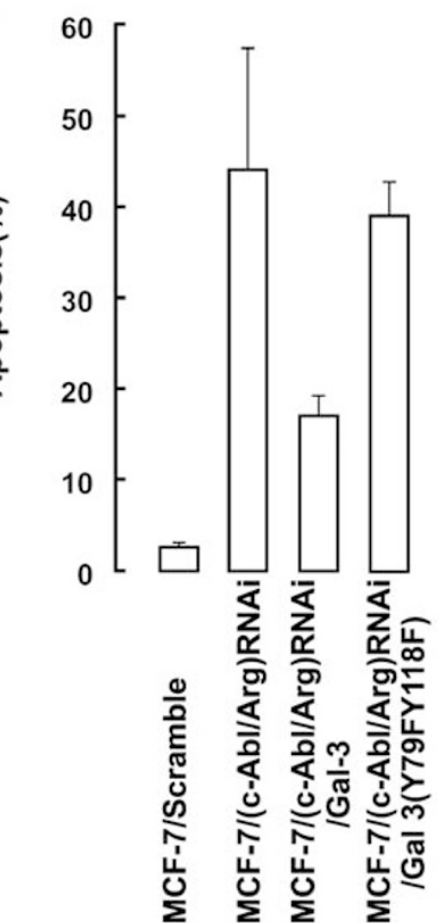

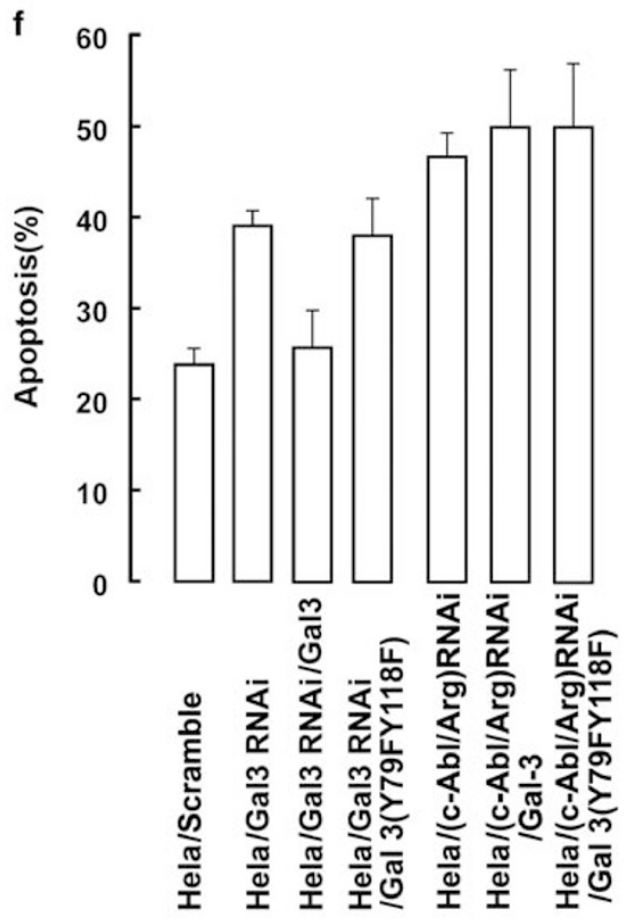

Figure 6 The c-Abl/Arg-mediated phosphorylation of Gal3 regulates cell apoptosis. (a) The indicated cells were treated with $10 \mathrm{~Gy}$ IR and harvested $48 \mathrm{~h}$ after treatment, and cell apoptosis was assessed by Sub-G1. (b) The indicated cells were treated with $4 \mu \mathrm{M}$ CDDP for $24 \mathrm{~h}$. Cell apoptosis was assessed by Sub-G1. (c) The indicated cells were treated with $1 \mu \mathrm{M}$ STS for $10 \mathrm{~h}$ and subjected to the caspase 2 (open bar) or caspase 6 (hatched bar) activation assay. The mean \pm S.D. of three experiments is presented. (d) Cells were treated with $1 \mu \mathrm{M}$ STS for $5 \mathrm{~h}$ for the cytochrome $c$ release assay or $10 \mathrm{~h}$ for other experiments. The cell lysates, or cytosol fraction for the cytochrome $c$ release assay, were analyzed by immunoblotting with the indicated antibody. (e) The indicated cells were treated with $0.5 \mu \mathrm{M} \mathrm{STS}$ for $12 \mathrm{~h}$ and apoptosis was assessed. (f) The indicated cells were treated with $1 \mu \mathrm{M}$ STS for $12 \mathrm{~h}$ and apoptosis was assessed

$(c-a b l+a r g)$ RNAi cells are more prone to apoptosis, tumor growth was significantly repressed (Figures $7 \mathrm{~b}, \mathrm{~d}$ ). Tumor growth could be slightly rescued by the expression of wild-type Gal3 but not Gal3(Y79FY118F) (Figures 7c, d).

\section{Discussion}

Gal3 has previously been associated with several apoptotic mechanisms. ${ }^{3,30,31}$ The phosphorylation of Gal3 at Ser6 and Ser12 by casein kinase has been extensively investi- 
a
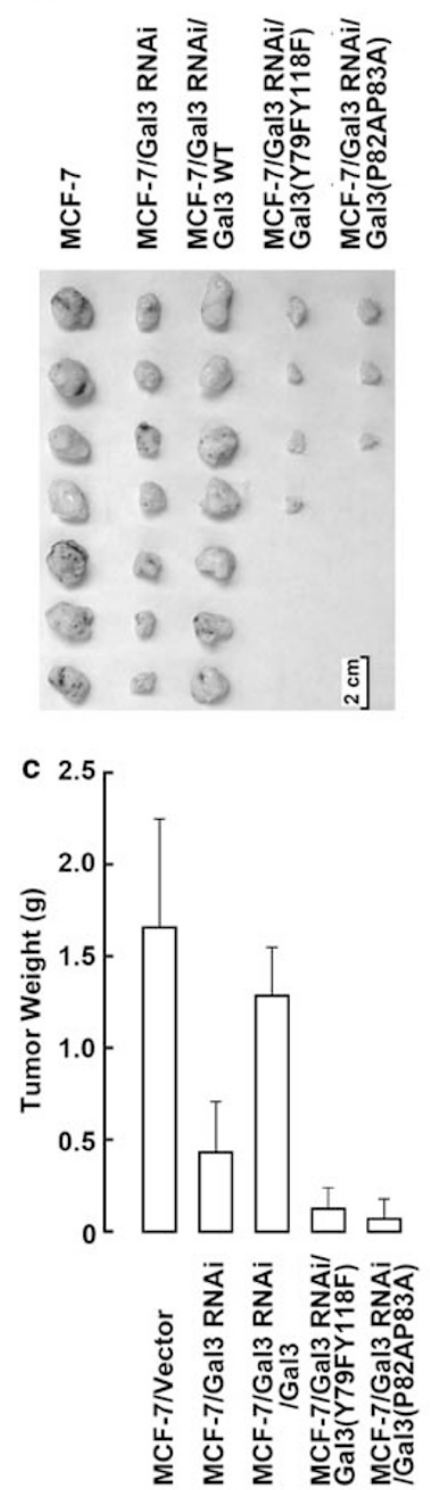

b
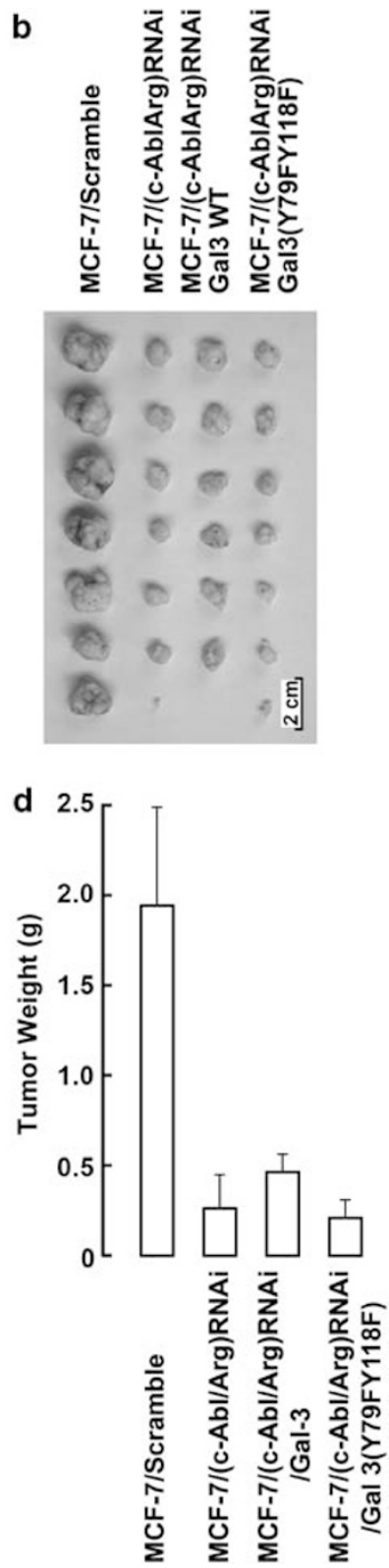

Figure 7 The c-Abl/Arg-mediated phosphorylation of Gal3 regulates tumorigenesis. (a-d) Female athymic nude mice (BALB/C nu/nu, 18-20 g) were subcutaneously inoculated at a single site with $5 \times 106$ cells as indicated. Tumors were surgically excised 21 days after inoculation (panels $a, b)$ and weighed (panels c, d)

gated. $^{32,33}$ In this study, we have shown that Gal3 is associated with and phosphorylated by c-Abl/Arg tyrosine kinases and the function of Gal3 in apoptosis, which is directly relevant to its association with the kinases.

Many of the other proteins that interact with and are phosphorylated by c-Abl are known to do so under stressrelated conditions. ${ }^{13}$ In contrast, the association of Gal3 with c-Abl and Arg is readily displayed, and strong tyrosine phosphorylation was also observed under steady-state conditions. These findings are relevant to physiological functions. Gal3 expression is downregulated in cells deficient in c-Abl or Arg, particularly in cells deficient in both tyrosine kinases. Both Gal3:Abl association and Gal3 tyrosine phosphorylation were significantly inhibited by high-level $\mathrm{H}_{2} \mathrm{O}_{2}$. CMA of Gal3 may have occurred in response to highlevel oxidative stress conditions or high-dosage IR treatment.

The effect of STI571 on Gal3 expression was nowhere near the effect of $\mathrm{Abl} / \mathrm{Arg}$ depletion, which suggests that, compared with the kinase activity, the presence of the Abl/Arg protein is more important in maintaining the intracellular levels of Gal3. The c-Abl/Arg-mediated phosphorylation of Gal3 may increase the Gal3 level by potentiating the c-Abl:Gal3 complex formation (Figures 1d-f). Cells deficient in either c-Abl or Arg were not as sensitive to the stimuli because the Gal3 levels were retained in the presence of either kinase. On the contrary, depleting c-Abl may result in attenuated apoptosis induced by DNA damage or oxidative stress through other

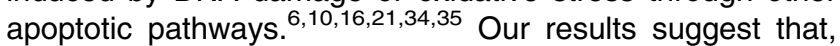
depending on the cellular context, c-Abl/Arg can be proapoptotic or antiapoptotic through different pathways, and c-Abl/ Arg-regulated lysosomal degradation of antiapoptotic Gal3 may provide one of the important arms in c-Abl/ Arg-dependent antiapoptotic pathways.

There are 14 members in the Galectins family that share remarkable sequence similarities in the carbohydrate-recognition domain. Galectins are capable of controlling cell death in eukaryotic development, immune system homeostasis, and tumorigenesis. ${ }^{36,37} \mathrm{Gal} 3$ is the only member in the Galectin family that acts as an anti-apoptotic molecule. It differs from other Galectins in that it contains two galactosebinding domains and, importantly, an NWGR motif that is highly conserved among members of the $\mathrm{Bcl} 2$ family. This motif may be essential for its antiapoptotic properties by preventing mitochondrial damage, cytochrome $c$ release, and caspase activation in response to various apoptotic stimuli. ${ }^{4}$ Gal1, on the other hand, induces apoptosis of activated human $T$ cells and human leukemia cells dependent on the expression of CD45. ${ }^{38}$ Downregulation of Gal1 induces lysosomal membrane permeabilization in B16F10 mouse melanoma cells, possibly by the repression of HSP70 transcription controlled by certain Gal1-targeted NFAT. ${ }^{39,40}$ In this study, c-Abl/Arg inhibitors induced lysosomal accumulation degradation of Gal3, with more HSP70 accumulated in the lysosomes (Figures 4 and $5 \mathrm{a}$ ). The structural difference between Gal3 and other Galectins may confer differential consequences.

Using xenograft models, we confirmed that c-Abl/Arg is important in Gal3-mediated tumor generation. The observation that tumor size is even further attenuated by the expression of Gal3(Y79FY118F) and Gal3(P82AP83A) may be indicative of a dominant-negative effect of the mutant protein. The expression of an N-terminal truncated Gal3 has previously been shown to have a dominant-negative effect. ${ }^{41}$ We also found that tumor growth could not be rescued by either wild-type or mutated Gal3 in c-Abl/Arg knockdown tumor cells, suggesting that the oncogenicity of Gal3 is dependent on the activity of c-Abl or Arg.

Gal3 is a tumorigenic protein that is overexpressed in many tumors. c-Abl inhibitor-induced lysosomal degradation of Gal3 may provide a new approach for tumor therapy. 


\section{Materials and Methods}

Cell culture and transfections. 293T, MCF-7, HeLa, H1299, and MEFs derived from wild-type, $c$-abl ${ }^{-1}$, and $c$-abl ${ }^{-1}$ arg $^{-1-}$ littermates ${ }^{16}$ were grown in Dulbecco's modified Eagle's medium (DMEM; Invitrogen, Carlsbad, CA, USA) supplemented with 10\% heat-inactivated fetal bovine serum (Hyclone, Mountain View, CA, USA), $2 \mathrm{mM}$ L-glutamine, 100 Units $/ \mathrm{ml}$ penicillin, and $100 \mu \mathrm{g} / \mathrm{ml}$ streptomycin. Transient transfections were performed with Lipofectamine 2000 (Invitrogen). Cells were also treated with STS, CDDP, 3MA, Concanamycin, lactocystin, PepA (all from Sigma, Louis, MO, USA) or STI571 (Novartis, ShangHai, China) as indicated.

Vectors and epitope tagging of proteins. Flag- or Myc-tagged c-Abl, Arg, Gal3, and their mutants were expressed by cloning the genes into the pcDNA3based Flag vector (Invitrogen) or pCMV-Myc (Clontech, Otsu, shiga, Japan). GST fusion proteins were generated by expression in pGEX4T-2-based vectors (Amersham Biosciences Biotech Inc., Piscataway, NJ, USA) in Escherichia coli BL21 (DE3). Site mutations in c-Abl and Gal3 genes were achieved by overlapping PCR.

Immunoprecipitation and immunoblot analysis. Cell lysates were prepared in lysis buffer $(50 \mathrm{mM}$ Tris- $\mathrm{HCl}(\mathrm{pH} 7.5), 1 \mathrm{mM}$ phenylmethylsulfonyl fluoride, $1 \mathrm{mM}$ dithiothreitol, $10 \mathrm{mM}$ sodium fluoride, $10 \mu \mathrm{g} / \mathrm{ml}$ aprotinin, $10 \mu \mathrm{g} / \mathrm{ml}$ leupeptin, and $10 \mu \mathrm{g} / \mathrm{ml}$ PepA) containing $1 \%$ Nonidet P-40. Soluble proteins were subjected to immunoprecipitation with anti-Flag (M2, Sigma), anti-Myc (9E10, Santa Cruz, Santa Cruz, CA, USA), anti-Gal3 (B2 mouse monoclonal antibody, Santa Cruz), or anti-c-Abl (K-12 rabbit polyclonal antibody, Santa Cruz). Normal rabbit IgG or normal mouse IgG of the same subclass (Santa Cruz) was used as the control. In addition, an aliquot of the total lysate $(5 \%, \mathrm{v} / \mathrm{v})$ was included as a control. Immunoblot analysis was performed with horseradish peroxidase (HRP)-conjugated anti-Myc (9E10, Santa Cruz), HRP-conjugated anti-Flag (M2, Sigma), anti- $\beta$-actin (Sigma), anti- $\alpha$-tubulin (Sigma), HRP-conjugated anti-P-Tyr (4G10, Upstate Biotechnology Inc., Temecula, CA, USA), anti-HSC70 (H-300, Santa Cruz), antiGal3 (H160, rabbit polyclonal antibody, Santa Cruz), anti-c-Abl (24-11, mouse monoclonal antibody, Santa Cruz), or anti-LamP2 (H4B4, Santa Cruz) antibody. The antigen-antibody complexes were visualized with chemiluminescence (PerkinElmer Life Sciences Inc., Waltham, MA, USA). TRUE Western marker (Vigorous) was used as a molecular weight standard.

To confirm that protein interaction occurred in the cells, $5 \times 10^{6}$ cells were treated with $1 \mathrm{ml} 1.0 \% \mathrm{w} / \mathrm{v}$ cross-linking paraformaldehyde (PFA) in PBS for $30 \mathrm{~min}$, and the reaction was stopped by adding glycine at a final concentration of $125 \mathrm{mM}$. Cell lysates were prepared in lysis buffer containing $25 \mathrm{mM}$ lactose, ${ }^{31}$ as described above, and the supernatants were subjected to immunoprecipitation. ${ }^{42}$

Protein-binding assays. In GST pull-down experiments, cell lysates were incubated for $2 \mathrm{~h}$ at $4^{\circ} \mathrm{C}$ with $2 \mu \mathrm{g}$ purified GST or GST fusion proteins bound to glutathione beads (GE Healthcare, Little Chalfont, Buckinghamshire, UK). The adsorbates were washed with lysis buffer and then subjected to SDS-PAGE and immunoblot analysis. An aliquot of the total lysate $(5 \%, v / v)$ was included as a loading control.

In direct binding assays, immunoprecipitates were separated by SDS-PAGE and then blotted onto nitrocellulose membranes. The membranes were subsequently incubated with purified GST fusion proteins for $2 \mathrm{~h}$ at room temperature. The GST fusion proteins binding to the nitrocellulose were probed with anti-GST antibody.

Kinase assays. Purified recombinant Gal3 $(0.5 \mu \mathrm{g}$; CytoLab Ltd, Rocky Hill, $\mathrm{NJ}$, USA) was incubated with recombinant c-Abl and Arg $(0.02 \mu \mathrm{g}$; Upstate Biotechnology Inc.) in kinase buffer (20 mM HEPES (pH 7.5), $75 \mathrm{mM} \mathrm{KCl}, 10 \mathrm{mM}$ $\mathrm{MgCl}_{2}$, and $10 \mathrm{mM} \mathrm{MnCl}_{2}$ ) containing $2.5 \mu \mathrm{Ci}$ of $\left[\gamma^{-32} \mathrm{P}\right]$ ATP for $30 \mathrm{~min}$ at $37^{\circ} \mathrm{C}$. The reaction products were analyzed by SDS-PAGE and autoradiography.

Pulse-chase assays. Cells were transfected with Flag-Gal3 or Gal3 mutants for $18 \mathrm{~h}$, and then incubated with methionine-free DMEM (Invitrogen) containing $10 \mu \mathrm{Ci} / \mathrm{ml}\left[{ }^{35} \mathrm{~S}\right]$ methionine (Amersham Biosciences Biotech Inc.) for $90 \mathrm{~min}$. The cells were then washed and cultured in complete DMEM and harvested at the indicated time points. Anti-Flag immunoprecipitates were subjected to SDS-PAGE and autoradiography. The bands were excised and subjected to liquid scintillation counting for quantitation.
LC/MS/MS. After the gel was stained with Coomassie Blue, the protein band was excised from the gel and minced into pieces. Dried gel pieces were incubated with $10 \mu \mathrm{l}$ porcine elastase (Roche, Indianapolis, IN, USA) for $16 \mathrm{~h}$ at $37^{\circ} \mathrm{C}$. The peptide mixtures were extracted by acetonitrile/water $(1: 1, \mathrm{v} / \mathrm{v})$ with $0.1 \%$ formic acid solution. Nano-LC-MS/MS analysis was carried out on an LC-Packing System (Dionex/LC Packings, Sunnyvale, CA, USA) coupled with a hybrid linear ion trap-7T Fourier transform ion cyclotron resonance mass spectrometer (LTQFTMS, Thermo Electron, Waltham, MA, USA). One full MS scan $\left(400-2000 \mathrm{~m} / \mathrm{z}, 10^{5}\right.$ resolution in ICR cell and automatic gain control (AGC) of $5 \times 10^{5}$ ) was followed by 10 datadependent MS/MS spectra in the linear ion trap from the 10 most abundant ions and with dynamic exclusion for $30 \mathrm{~s}$. Singly charged ions were rejected. Data were analyzed by searching against the database using a local Mascot search engine (v2.1, Matrix Science, Boston, MA, USA) filtered by a mascot score $\geqslant 25$. The filtered phosphopeptides were validated by manually interpreting the MS/MS spectra.

Immunofluorescence and confocal microscopy. The immunofluorescent staining of cells was performed as described previously. ${ }^{43}$ Briefly, the cells were fixed with $4 \%$ PFA for 15 min, permeabilized with $0.5 \%$ Triton $X-100$ for $10 \mathrm{~min}$, and blocked with $1 \%$ goat serum albumin in PBS for $30 \mathrm{~min}$. Anti-Gal3, antiLamp2, anti-HSC70, or anti-LC3 (Abgent, San Diego, CA, USA) antibody was added and incubated for $1 \mathrm{~h}$ at room temperature. FITC- or TRITC-conjugated goat anti-mouse or anti-rabbit immunoglobulin (Jackson ImmunoResearch Inc., West Grove, Pennsylvania, USA) was added and incubated for another $1 \mathrm{~h}$. Confocal microscopy was performed using a Bio-Rad Radiance 2100 microscope (Bio-Rad, Hercules, CA, USA) equipped with a $\times 150$ objective lens. The percentage of Gal3 accumulated in lysosomes or with HSP70 was assessed by densitometry (Tanon, Ver2.0, Shang hai, China).

Preparation of lysosomes. Lysosomes were prepared from cells by Percoll/ metrizamide gradient centrifugation as described previously. ${ }^{44}$ Briefly, $2 \times 10^{7}$ cells were incubated with hypotonic buffer and homogenized with a B-type Dounce homogenizer. The homogenate was centrifuged at $1300 \mathrm{~g}$ for $5 \mathrm{~min}$, and the supernatant was subjected to centrifugation using hybrid Percoll-metrizamide sequential density gradients at $50500 \mathrm{~g}$ for $15 \mathrm{~min}$ at $4^{\circ} \mathrm{C}$, and then the interfaces were collected.

Apoptosis assay. The DNA content of the cell was assessed by staining ethanol-fixed and citrate buffer-treated cells with propidium iodide and monitoring by FACScan (Becton-Dickinson, Franklin Lakes, NJ, USA). The number of cells with sub-G1 DNA, an indicator of apoptotic cells, was determined with a MODFIT LT program. The percentage of apoptotic cells was expressed as the mean \pm S.D. of three experiments.

Cytochrome $c$ release assay. Cell pellets were resuspended in $1 \mathrm{ml}$ icecold buffer A (250 mM sucrose, $20 \mathrm{mM}$ HEPES (pH 7.4), $10 \mathrm{mM} \mathrm{KCl}, 1.5 \mathrm{mM} \mathrm{MgCl}$, $1 \mathrm{mM}$ EDTA, $1 \mathrm{mM}$ EGTA, $1 \mathrm{mM}$ dithiothreitol, $170 \mu \mathrm{g} / \mathrm{ml}$ phenylmethylsulfonyl fluoride, $16 \mu \mathrm{g} / \mathrm{ml}$ aprotinin, and $4 \mu \mathrm{g} / \mathrm{ml}$ leupeptin) and incubated for $10 \mathrm{~min}$ on ice. Cells were lysed by a Wheaton overhead stirrer (Wheaton, Wheaton, IL, USA). Unlysed cells and nuclei were pelleted at $120 \mathrm{~g}$ for $10 \mathrm{~min}$ at $4^{\circ} \mathrm{C}$. The supernatant was centrifuged at $10000 \mathrm{~g}$ at $4^{\circ} \mathrm{C}$ for $25 \mathrm{~min}$, and then at $100000 \mathrm{~g}$ for $1 \mathrm{~h}$ at the same temperature. Equal amounts of the supernatant were subjected to western blotting with anti-cytochrome $c$.

Caspase activation assay. A total of $3 \times 10^{6}$ cells were treated with STS for $10 \mathrm{~h}$, resuspended in $50 \mu \mathrm{l}$ of cell lysis buffer from the Caspase Fluorometric Assay Kit (Biovision, Mountain View, CA, USA), and then incubated for 10 min on ice. A $100 \mu$ laliquot of the cell lysate was incubated with caspase substrates (caspase 2, VDVAD-AFC; caspase 6, VEID-AFC; caspase 12, ATAD-AFC) for $2 \mathrm{~h}$. Relative fluorescence was assayed at an excitation wavelength of $400 \mathrm{~nm}$ and an emission wavelength of $505 \mathrm{~nm}$ using a fluorescence spectrometer (Thermo Fluoroskan, Waltham, MA, USA). Relative fluorescence intensity was calculated as the mean \pm S.D. of three experiments.

In vivo tumorigenicity assay. Female athymic nude mice (Balb/c nu/nu, 18$20 \mathrm{~g}$ ) were randomly divided into groups and subcutaneously inoculated at a single site with $5 \times 10^{6}$ tumor cells. Tumor diameter was measured weekly using calipers until 21 days when the tumor weight was also determined after dissection. 
RNA interference. The siRNA sequences targeting mRNAs were as follows Gal3, GCTCACTTGTTGCAGTACA; c-Abl and Arg (co-RNAi), GGGAAATTGCT ACCTATGG, which is $100 \%$ homologous between c-Abl and Arg; and the nonsilencing scramble sequence, GTGACATAGCAGGAACTAC. These sequences were cloned into the pSUPER-retro-neo plasmid (OligoEngine Inc., Seattle, WA, USA) or psiSTRIKETM-Hygromycin Vector (Promega, Madison, WI, USA). The rescue of Gal3 or its mutants was achieved by the stable transfection of the expression vector in which three nucleotides in the Gal3 targeting sequences were mutated without any amino-acid changes. Stable cell lines were obtained by treating the cells with $800 \mu \mathrm{g} / \mathrm{ml} \mathrm{G} 418,50 \mu \mathrm{g} / \mathrm{ml}$ hygromycin B, and $/$ or $2 \mu \mathrm{g} / \mathrm{ml}$ puromycin. Individual clones were picked and identified by RT-PCR and western blot for the relevant protein.

\section{Conflict of interest}

The authors declare no conflict of interest.

Acknowledgements. This investigation was supported by Grant nos 30730027 and 3027316 awarded by the Natural Science Foundation of China. We acknowledge Donald Kufe for insightful discussions and Dr. Tony Koleske for providing the $\mathrm{c}-\mathrm{abl} \mathrm{C}^{-1-}, \mathrm{arg}^{-1-}$ and $\mathrm{c}-\mathrm{abl}{ }^{-1-} \mathrm{arg}^{-1-}$ MEF cells. We greatly acknowledge David Weaver for his help in preparing the paper. None of the authors have a financial interest in this work.

1. Nangia-Makker P, Honjo Y, Sarvis R, Akahani S, Hogan V, Pienta KJ et al. Galectin-3 induces endothelial cell morphogenesis and angiogenesis. Am J Pathol 2000; 156: 899-909.

2. Liu FT, Rabinovich GA. Galectins as modulators of tumour progression. Nat Rev Cancer 2005; 5: 29-41.

3. Akahani S, Nangia-Makker P, Inohara H, Kim HR, Raz A. Galectin-3: a novel antiapoptotic molecule with a functional BH1 (NWGR) domain of Bcl-2 family. Cancer Res 1997; 57 5272-5276.

4. Yu F, Finley Jr RL, Raz A, Kim HR. Galectin-3 translocates to the perinuclear membranes and inhibits cytochrome $c$ release from the mitochondria. A role for synexin in galectin-3 translocation. J Biol Chem 2002; 277: 15819-15827.

5. Van Etten RA. Cycling, stressed-out and nervous: cellular functions of c-Abl. Trends Cell Biol 1999; 9: 179-186.

6. Pendergast AM. The Abl family kinases: mechanisms of regulation and signaling Adv Cancer Res 2002; 85: 51-100.

7. Wang JY. Regulation of cell death by the Abl tyrosine kinase. Oncogene $2000 ; 19$ 5643-5650.

8. Pendergast AM. Stress and death: breaking up the c-Abl/14-3-3 complex in apoptosis. Nat Cell Biol 2005; 7: 213-214.

9. Goga A, Liu X, Hambuch TM, Senechal K, Major E, Berk AJ et al. p53 dependent growth suppression by the c-Abl nuclear tyrosine kinase. Oncogene 1995; 11: 791-799.

10. Yuan ZM, Huang Y, Fan MM, Sawyers C, Kharbanda S, Kufe D. Genotoxic drugs induce interaction of the $\mathrm{c}-\mathrm{Abl}$ tyrosine kinase and the tumor suppressor protein p53. J Biol Chem 1996; 271: 26457-26460.

11. Yuan ZM, Shioya $H$, Ishiko $T$, Sun $X, G u J$, Huang $Y Y$ et al. p73 is regulated by tyrosine kinase c-Abl in the apoptotic response to DNA damage. Nature 1999; 399: 814-817.

12. Agami R, Blandino G, Oren $M$, Shaul $Y$. Interaction of $c-A b l$ and p73alpha and their collaboration to induce apoptosis. Nature 1999; 399: 809-813.

13. Sun $X$, Majumder $P$, Shioya $H$, Wu F, Kumar $S$, Weichselbaum $R$ et al. Activation of the cytoplasmic c-Abl tyrosine kinase by reactive oxygen species. J Biol Chem 2000; 275 : 17237-17240

14. Cao C, Leng Y, Kufe D. Catalase activity is regulated by c-Abl and Arg in the oxidative stress response. J Biol Chem 2003; 278: 29667-29675.

15. Dorsch M, Goff SP. Increased sensitivity to apoptotic stimuli in c-abl-deficient progenitor Bcell lines. Proc Natl Acad Sci USA 1996; 93: 13131-13136.

16. Koleske AJ, Gifford AM, Scott ML, Nee M, Bronson RT, Miczek KA et al. Essential roles for the Abl and Arg tyrosine kinases in neurulation. Neuron 1998; 21: 1259-1272.

17. Amarante-Mendes GP, Naekyung Kim C, Liu L, Huang Y, Perkins CL, Green DR et al. $\mathrm{Bcr}-\mathrm{Abl}$ exerts its antiapoptotic effect against diverse apoptotic stimuli through blockage of mitochondrial release of cytochrome $C$ and activation of caspase-3. Blood 1998; 91: $1700-1705$

18. Van Etten RA, Jackson $P$, Baltimore $D$. The mouse type IV $\mathrm{c}$-abl gene product is a nuclear protein, and activation of transforming ability is associated with cytoplasmic localization. Cell 1989; 58: 669-678

19. McGahon A, Bissonnette R, Schmitt M, Cotter KM, Green DR, Cotter TG. BCR-ABL maintains resistance of chronic myelogenous leukemia cells to apoptotic cell death. Blood 1994; 83: 1179-1187.

20. Barila D, Superti-Furga G. An intramolecular SH3-domain interaction regulates c-Abl activity. Nat Genet 1998; 18: 280-282.

21. Deng X, Hofmann ER, Villanueva A, Hobert O, Capodieci P, Veach DR et al. Caenorhabditis elegans ABL-1 antagonizes p53-mediated germline apoptosis after ionizing irradiation. Nat Genet 2004; 36: 906-912.

22. Gong JG, Costanzo A, Yang HQ, Melino G, Kaelin WG, Jr., Levrero M, Wang JY. The tyrosine kinase c-Abl regulates p73 in apoptotic response to cisplatin-induced DNA damage. Nature 1999; 399: 806-809.

23. Vigneri $P$, Wang JY. Induction of apoptosis in chronic myelogenous leukemia cells through nuclear entrapment of BCR-ABL tyrosine kinase. Nat Med 2001; 7: 228-234.

24. Barila D, Rufini A, Condo I, Ventura N, Dorey K, Superti-Furga G et al. Caspase-dependent cleavage of C-Abl contributes to apoptosis. Mol Cell Biol 2003; 23: 2790-2799.

25. Baskaran R, Wood LD, Whitaker LL, Canman CE, Morgan SE, Xu Y et al. Ataxia telangiectasia mutant protein activates $\mathrm{C}-\mathrm{Abl}$ tyrosine kinase in response to ionizing radiation. Nature 1997; 387: 516-519.

26. Majeski AE, Dice JF. Mechanisms of chaperone-mediated autophagy. Int J Biochem Cell Biol 2004; 36: 2435-2444.

27. Agarraberes FA, Terlecky SR, Dice JF. An intralysosomal hsp70 is required for a selective pathway of lysosomal protein degradation. J Cell Biol 1997; 137: 825-834.

28. Mooney LM, Al-Sakkaf KA, Brown BL, Dobson PR. Apoptotic mechanisms in T47D and MCF-7 human breast cancer cells. Br J Cancer 2002; 87: 909-917.

29. Nakahara S, Oka N, Raz A. On the role of galectin-3 in cancer apoptosis. Apoptosis 2005; 10: $267-275$

30. Fukumori T, Takenaka Y, Oka N, Yoshii T, Hogan V, Inohara H et al. Endogenous galectin3 determines the routing of CD95 apoptotic signaling pathways. Cancer Res 2004; 64 : 3376-3379.

31. Yang RY, Hsu DK, Liu FT. Expression of galectin-3 modulates T-cell growth and apoptosis. Proc Natl Acad Sci USA 1996; 93: 6737-6742.

32. Huflejt ME, Turck CW, Lindstedt R, Barondes SH, Leffler H. L-29, a soluble lactose-binding lectin, is phosphorylated on serine 6 and serine 12 in vivo and by casein kinase I. J Biol Chem 1993; 268: 26712-26718.

33. Yoshii T, Fukumori T, Honjo Y, Inohara H, Kim HR, Raz A. Galectin-3 phosphorylation is required for its anti-apoptotic function and cell cycle arrest. J Biol Chem 2002; 277: 6852-6857.

34. Raina D, Ahmad R, Kumar S, Ren J, Yoshida K, Kharbanda S et al. MUC1 oncoprotein blocks nuclear targeting of $\mathrm{c}-\mathrm{Abl}$ in the apoptotic response to DNA damage. EMBO J 2006; 25: 3774-3783.

35. Huang Y, Yuan ZM, Ishiko T, Nakada S, Utsugisawa T, Kato T et al. Pro-apoptotic effect of the c-Abl tyrosine kinase in the cellular response to 1-beta-D-arabinofuranosylcytosine. Oncogene 1997; 15: 1947-1952.

36. Hernandez JD, Baum LG. Ah, sweet mystery of death! Galectins and control of cell fate. Glycobiology 2002; 12: 127R-136R

37. Rabinovich GA, Toscano MA. Turning 'sweet' on immunity: galectin-glycan interactions in immune tolerance and inflammation. Nat Rev Immunol 2009; 9: 338-352.

38. Perillo NL, Pace KE, Seilhamer JJ, Baum LG. Apoptosis of T cells mediated by galectin-1. Nature 1995; 378: 736-739.

39. Mathieu V, Le Mercier M, De Neve N, Sauvage S, Gras T, Roland I et al. Galectin-1 knockdown increases sensitivity to temozolomide in a B16F10 mouse metastatic melanoma model. J Invest Dermatol 2007; 127: 2399-2410.

40. Le Mercier M, Lefranc F, Mijatovic T, Debeir O, Haibe-Kains B, Bontempi G et al. Evidence of galectin-1 involvement in glioma chemoresistance. Toxicol Appl Pharmacol 2008; 229: 172-183.

41. Hoyer KK, Pang M, Gui D, Shintaku IP, Kuwabara I, Liu FT et al. An anti-apoptotic role for galectin-3 in diffuse large B-cell lymphomas. Am J Pathol 2004; 164: 893-902.

42. Vasilescu J, Guo X, Kast J. Identification of protein-protein interactions using in vivo crosslinking and mass spectrometry. Proteomics 2004; 4: 3845-3854.

43. Tsay YG, Lin NY, Voss PG, Patterson RJ, Wang JL. Export of galectin-3 from nuclei of digitonin-permeabilized mouse 3T3 fibroblasts. Exp Cell Res 1999; 252: 250-261.

44. Storrie B, Madden EA. Isolation of subcellular organelles. Methods Enzymol 1990; 182: 203-225.

\section{Supplementary Information accompanies the paper on Cell Death and Differentiation website (http://www.nature.com/cdd)}

